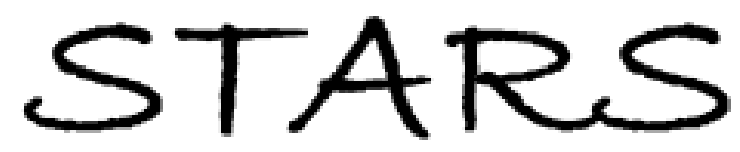

University of Central Florida

STARS

$1-1-2008$

\title{
Electron-beam lithography of multiple-layer submicrometer periodic arrays on a barium fluoride substrate
}

\author{
J. S. Tharp \\ University of Central Florida \\ D. J. Shelton \\ University of Central Florida \\ S. L. Wadsworth \\ University of Central Florida \\ G. D. Boreman \\ University of Central Florida
}

Find similar works at: https://stars.library.ucf.edu/facultybib2000

University of Central Florida Libraries http://library.ucf.edu

This Editorial Material is brought to you for free and open access by the Faculty Bibliography at STARS. It has been accepted for inclusion in Faculty Bibliography 2000s by an authorized administrator of STARS. For more information, please contact STARS@ucf.edu.

\section{Recommended Citation}

Tharp, J. S.; Shelton, D. J.; Wadsworth, S. L.; and Boreman, G. D., "Electron-beam lithography of multiplelayer submicrometer periodic arrays on a barium fluoride substrate" (2008). Faculty Bibliography 2000 s. 1055.

https://stars.library.ucf.edu/facultybib2000/1055

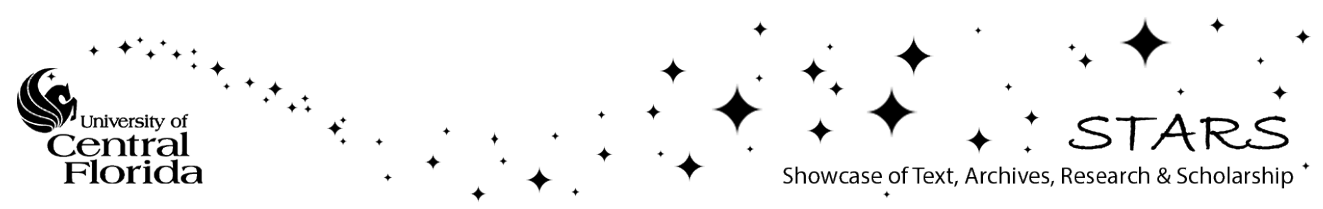




\section{Electron-beam lithography of multiple-layer submicrometer periodic arrays on a barium fluoride substrate}

J. S. Tharp, D. J. Shelton, S. L. Wadsworth, and G. D. Boreman

Citation: Journal of Vacuum Science \& Technology B: Microelectronics and Nanometer Structures Processing, Measurement, and Phenomena 26, 1821 (2008); doi: 10.1116/1.2966431

View online: https://doi.org/10.1116/1.2966431

View Table of Contents: https://avs.scitation.org/toc/jvn/26/5

Published by the American Institute of Physics

\section{ARTICLES YOU MAY BE INTERESTED IN}

Barium fluoride and strontium fluoride negative electron beam resists

Journal of Vacuum Science \& Technology B: Microelectronics Processing and Phenomena 5, 374 (1987); https:// doi.org/10.1116/1.583906 


\title{
SHOP NOTES
}

These are "how to do it" papers. They should be written and illustrated so that the reader may easily follow whatever

instruction or advice is given.

\section{Electron-beam lithography of multiple-layer submicrometer periodic arrays on a barium fluoride substrate}

\author{
J. S. Tharp, D. J. Shelton, ${ }^{\text {a) }}$ S. L. Wadsworth, and G. D. Boreman \\ College of Optics and Photonics/CREOL, University of Central Florida, Orlando, Florida 32817-2700
}

(Received 3 March 2008; accepted 10 July 2008; published 6 October 2008)

[DOI: $10.1116 / 1.2966431]$

\section{INTRODUCTION}

Direct-write electron-beam fabrication of periodic arrays of submicrometer metallic structures onto $\mathrm{Si}$ wafers has been demonstrated $^{1-3}$ for use as infrared (IR) frequency selective surfaces (FSSs). Typically these fabrications have used Si for convenience and because of its broad spectral range of IR transparency from 2 to past $14 \mu \mathrm{m}$. However, the high refractive index (3.4) of $\mathrm{Si}$ is not ideal for some applications because it implies a high surface reflectance and also because of the resulting shrinkage of structure sizes to maintain a given electrical size when fabricated on the Si/air interface. The goal of this work was to explore the feasibility of using $\mathrm{BaF}_{2}$ as a low-index substrate material in multiple-layer FSS designs. While $\mathrm{BaF}_{2}$ has low index (1.4) and good transmission in the IR, it presents unique fabrication issues including difficulties of obtaining a return from a laser-based height monitor, susceptibility to thermal shock, and attack by etchants. We present procedures we used to successfully fabricate submicron metallic arrays on $\mathrm{BaF}_{2}$ in both single-layer and multiple-layer configurations.

\section{BARIUM FLUORIDE OPTICAL AND PHYSICAL PROPERTIES}

The $\mathrm{BaF}_{2}$ wafers were obtained from Global Optics (UK) with the following dimensions: $50.4 \mathrm{~mm}$ diameter $\pm 0.1 \mathrm{~mm}$, thickness of $3.10 \mathrm{~mm}+0.00 /-0.05 \mathrm{~mm}$. The wafers were also specified to be optically flat $(\lambda / 10$ at $633 \mathrm{~nm})$ which more than satisfied optical flatness requirements at IR wavelengths. The optical properties of the wafers used were measured using an IR variable-angle spectroscopic ellipsometer. The measured results for the optical constants, $n$ (refractive index) and $k$ (extinction coefficient), are shown in Fig. 1. As measured, $\mathrm{BaF}_{2}$ is sufficiently transparent from 2 to $12 \mu \mathrm{m}$ to be appropriate for use in transmissive IR FSS structures.

The physical properties of $\mathrm{BaF}_{2}$ were also of interest from the point of view of their impact on the lithographic process. $\mathrm{BaF}_{2}$ is susceptible to thermal shock because of the low thermal conductivity, $7.1 \mathrm{~W} \mathrm{~m}^{-1} \mathrm{C}^{-1}$, and the high thermal ex-

\footnotetext{
a)Electronic mail: dshelton@ @reol.ucf.edu
}

pansion coefficient, $18 \times 10^{-6} \mathrm{C}^{-1}{ }^{4}$ As a comparison, Si has a thermal conductivity of $159 \mathrm{~W} \mathrm{~m}^{-1} \mathrm{C}^{-1}$ and a thermal expansion coefficient of $2.55 \times 10^{-6} \mathrm{C}^{-1}{ }^{5}$ Therefore care was taken to prevent thermal-stress fracturing of the wafer when heating and cooling the substrate during the lithographic processing. Another relevant physical property is that $\mathrm{BaF}_{2}$ is soluble in both acids and bases. ${ }^{6}$

\section{ELECTRON-BEAM LITHOGRAPHY ON BAF ${ }_{2}$}

The FSS fabricated onto the $\mathrm{BaF}_{2}$ substrate had a minimum feature size of $500 \mathrm{~nm}$. The e-beam lithography tool used was a Leica EBPG 5000+ which is capable of line widths as small as $20 \mathrm{~nm}^{7}$ To write the structure with good edge definition, a spot size of approximately $100 \mathrm{~nm}$ was used with an approximately $100 \mathrm{nA}$ beam current at an accelerating voltage of $50 \mathrm{kV}$. The resist used was ZEP520A-7 with a thickness of $300 \mathrm{~nm}$.

To ensure good fidelity of the written pattern, it is important to create a route to ground for the incident electrons, which avoids charge-accumulation artifacts. Since $\mathrm{BaF}_{2}$ is nonconductive, a conductive layer was required. In addition, the electron beam has to be precisely focused onto the surface being written to yield minimum beam-spot size and proper dosage calibration. The e-beam writer measures the local height to the surface using a visible laser at $\lambda$ $=633 \mathrm{~nm}$ and a quad-cell detector. Thus, the surface to be written must be sufficiently reflective to allow good height measurements. Because of the high transparency and low refractive index of $\mathrm{BaF}_{2}$ at visible wavelengths, there was not enough power reflected to allow measurement of the surface height.

To remedy the issues of both the electron charging and the reflection of the surface, two methods were used to enable writing onto the $\mathrm{BaF}_{2}$ surface. The first remedy was to coat the entire resist surface with thin layer of nickel. The other technique was to use a spin-on conductive polymer, ${ }^{8}$ AquaSave, along with a ring of sputtered nickel outside the region to be written. Each of these techniques will be discussed for their merits and limitations for e-beam lithography on the $\mathrm{BaF}_{2}$ substrate. 


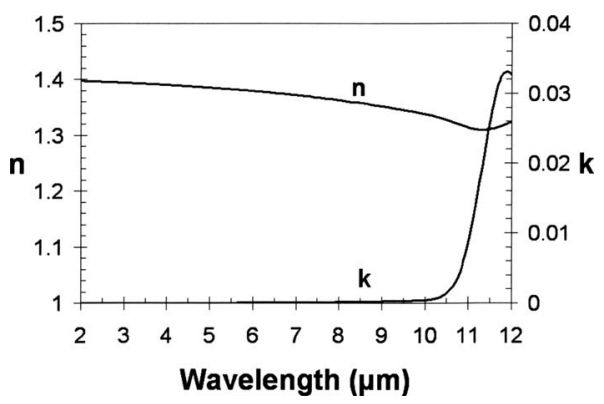

FIG. 1. Measured optical properties of the $\mathrm{BaF}_{2}$ substrate in the range of $2-12 \mu \mathrm{m}$ showing the refractive index $n$ and extinction coefficient $\kappa$.

The first method involved sputtering a $40 \mathrm{~nm}$ thickness layer of Ni onto the resist, using a Materials Research Corporation 8667 sputtering system. The advantage of using a full overcoat of $\mathrm{Ni}$ is that one can write on the entire surface of the wafer. The difficulty with using the full coat of $\mathrm{Ni}$ directly on the resist is that $\mathrm{Ni}$ must be removed before development of the resist. We tried two methods to remove the Ni layer. The first method was to wet etch Ni using Transene TFA nickel etchant, a nitric acid solution. Unfortunately, the etchant was found to aggressively attack the $\mathrm{BaF}_{2}$ wafer, ruining the surface quality within seconds. The second method was to remove $\mathrm{Ni}$ using $46 \mathrm{~cm}$ width adhesive tape (Controlled Environment Equipment Corp., polyfoam sticky roller), which is generally used to remove particles from cleanroom floors. Its width made it ideal for removal of the Ni layer from above the ZEP, since it was wider than the wafer's diameter. Ni adheres very poorly to ZEP resist compared to its adherence to the tape, and thus the metal is readily removed from the surface of the resist using the tape. However, it is important that the tape be used only once over the surface. When the tape is used only once, by making the size of the tape larger than the surface of the wafer, the tape adhesive never comes into contact with the resist layer. If used repeatedly, the adhesive will come into contact with the resist and one of two problems will occur. The first problem will be the potential removal of resist since the resist adheres to the tape more strongly than the resist adheres to the substrate. The second problem is that remnants of the adhesive will remain on the surface of the resist which will prevent the development of those regions. After $\mathrm{Ni}$ is removed, the surface is ready for development.

The second method was to spin on a conductive polymer, AquaSave, above the ZEP resist layer. The AquaSave was spun onto the wafer at $3000 \mathrm{rpm}$ and then baked at $110^{\circ} \mathrm{C}$ for $90 \mathrm{~s}$. After baking, the hotplate was set to cool slowly at a rate of about $4{ }^{\circ} \mathrm{C} / \mathrm{min}$ until room temperature was reached to prevent the $\mathrm{BaF}_{2}$ wafer from cracking from thermal shock. Once the wafer returned to room temperature, a circular piece of $\mathrm{Al}$ foil was used as a crude mask. The foil was simply placed over the center of the wafer and $40 \mathrm{~nm}$ of $\mathrm{Ni}$ was sputtered onto the surface. This method allowed for a conductive discharge layer, the conductive polymer, over the entire wafer while having only an optically reflective $\mathrm{Ni}$ layer at the edge of the wafer. The e-beam writer used a
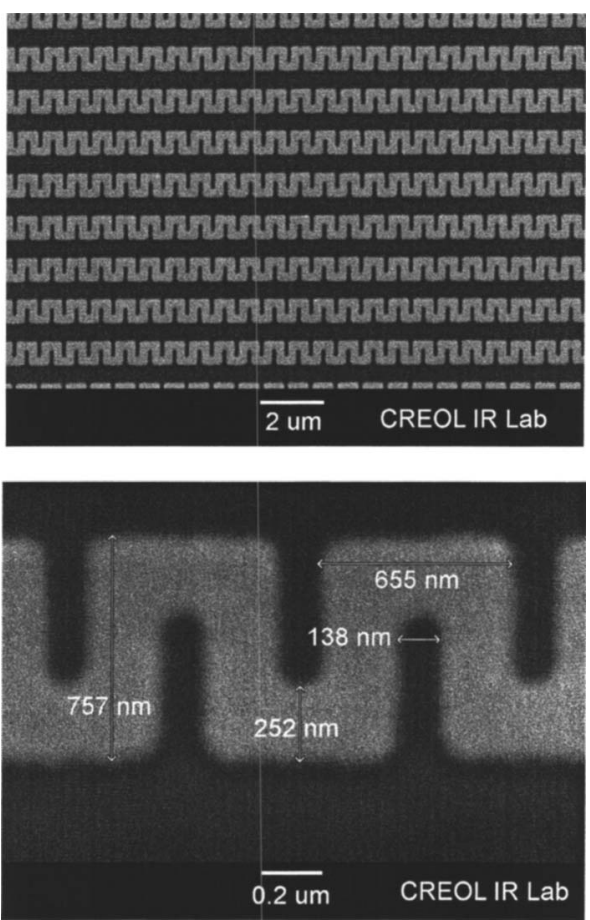

FIG. 2. Electron micrographs of the $\mathrm{Al}$ array structure on the $\mathrm{BaF}_{2}$ substrate.

modified program to determine the wafer height. The modification was to measure heights at the edge of the wafer in the regions of sputtered $\mathrm{Ni}$ and to fit these points to a plane. This approach worked since the wafer was substantially flat. The planar fit function was then used to compute the height at each location on the wafer and to modify the beam focus accordingly. The advantage for this method is in multiplelayer lithography, since one can see through the AquaSave layer for alignment purposes. Therefore the conductive polymer was used for the second layer in the double-layer FSS design, but the whole-surface Ni coating was used for the first layer write, since this process required one less heating and cooling cycle.

The developer used was ZEP-RD and the development time was $30 \mathrm{~s}$. With this development time, the dose used was $90 \mu \mathrm{C} / \mathrm{cm}^{2}$. After development, the wafer was barrel etched in an $\mathrm{O}_{2}$ plasma for $2 \mathrm{~min}$ at a rf power of $200 \mathrm{~W}$ using a Branson barrel etcher. This final etch was to remove any remaining resist in the developed regions.

Following the development and barrel etching, Al was deposited via a thermal evaporation to a thickness of $75 \mathrm{~nm}$. Once metallized, the wafer was placed into a bath of methylene chloride $\left(\mathrm{CH}_{2} \mathrm{Cl}_{2}\right)$ to remove the resist, leaving the desired structures on the $\mathrm{BaF}_{2}$ surface. Images of the fabricated structures are shown in Fig. 2. Once the first FSS layer was written, a second FSS layer could be fabricated once a standoff layer was deposited.

\section{MULTIPLE-LAYER LITHOGRAPHY ON BAF ${ }_{2}$}

For fabrication of multiple-layer FSS structures, we used a dielectric standoff material that had desirable optical properties (low absorption in the IR band of interest and similar 
refractive index to $\mathrm{BaF}_{2}$ ), which could be deposited in various thicknesses and which had good adherence to the substrate and to the metallic FSS structures. We used a spin-on dielectric from Dow Chemical Company, CYCLOTENE 3022-35, a benzocyclobutene (BCB) polymer. The optical properties of the BCB layer were previously presented. ${ }^{3}$ Since BCB can be spun onto a wafer, the thickness can be controlled by the spin speed. Also, the capability to spin on the dielectric layer as a liquid also allows for a much smoother top-surface topography; this planarization is very helpful for subsequent e-beam lithographic steps. ${ }^{9}$ Neither sputtering nor evaporation was suitable for deposition of the standoff layer because these processes produce conformal films, with the top surface of the deposited dielectric having the same topography as the underlying surface.

The process for deposition of a BCB layer with a thickness of $1.3 \mu \mathrm{m}$ began with an application of adhesion promoter (Dow AP3000), which was spun on at $2000 \mathrm{rpm}$ for $20 \mathrm{~s}$. The BCB was then applied with a spin speed of $3000 \mathrm{rpm}$ to achieve the desired thickness, using the viscosity of the undiluted product. Following the spin, BCB requires two heating steps to cure the polymer. The first step is to drive off the solvent (mesitylene) using a low-temperature bake at $180{ }^{\circ} \mathrm{C}$ for $5 \mathrm{~min}$ on a hotplate. Without removing the wafer, the temperature was then increased to $250{ }^{\circ} \mathrm{C}$ to cure the BCB. For this step the substrate was covered with a glass dish, incorporating a low-pressure $\mathrm{N}_{2}$ gas flow to prevent ambient $\mathrm{O}_{2}$ from reacting with the surface, which would otherwise reduce the IR transmission of the BCB.
Once the BCB layer is applied, the lithographic process discussed above was repeated for the second layer. The AquaSave conductive polymer was used as the conductive layer and a ring of $\mathrm{Ni}$ was sputtered onto the outer edge to allow for the surface height determination, while preserving the advantage of through-layer alignment.

\section{SUMMARY}

We explored fabrication-process options for use of $\mathrm{BaF}_{2}$ when used in direct-write electron-beam lithography. This material is of interest for IR FSS applications because of its low refractive index and high IR transparency. Challenges in the use of this material include its low conductivity, low reflectivity, attack by solvents, and sensitivity to thermal shock. Single- and double-layer submicrometer FSS struc-

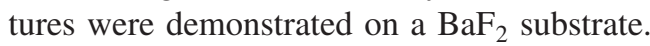

${ }^{1}$ B. Monacelli, J. Pryor, B. Munk, D. Kotter, and G. Boreman, IEEE Trans. Antennas Propag. 53, 745 (2005).

${ }^{2}$ J. Tharp, J. Lopez-Alonso, J. Ginn, B. Lail, C. Middleton, B. Munk, and G. Boreman, Opt. Lett. 31, 2687 (2006)

${ }^{3}$ D. Shelton, J. Tharp, G. Zummo, W. Folks, and G. Boreman, J. Vac. Sci. Technol. B 25, 1827 (2007).

${ }^{4}$ D. T. Morelli and J. Heremans, J. Appl. Phys. 63, 573 (1988).

${ }^{5}$ CRC Handbook of Chemistry and Physics, 84th ed. (CRC, Boca Raton, FL, 2003).

${ }^{6}$ T. E. Thorpe, A Dictionary of Applied Chemistry (Longmans, Green, New York, 1921)

${ }^{7}$ B. E. Maile, W. Henschel, H. Kurz, B. Rienks, R. Polman, and P. Kaars, Jpn. J. Appl. Phys., Part 1 39, 6836 (2000).

${ }^{8}$ S. Shimizu, T. Saitoh, M. Uzawa, M. Yuasa, K. Yano, T. Maruyama, and K. Wantanbe, Synth. Met. 85, 1337 (1997).

${ }^{9}$ D. J. Perettie, M. F. McCulloch, and P. E. Garrou, Proc. SPIE 1665, 331 (1992). 